\title{
New microsatellite loci for the mandarin fish Siniperca chuatsi and their application in population genetic analysis
}

\author{
C.X. Tian, X.-F. Liang, M. Yang, Y.Q. Dou, H.Z. Zheng, L. Cao, \\ Y.C. Yuan and C. Zhao \\ College of Fisheries, Key Lab of Freshwater Animal Breeding, \\ Ministry of Agriculture, Huazhong Agricultural University, \\ Hubei Collaborative Innovation Center for Freshwater Aquaculture, \\ Wuhan, Hubei, China
}

Corresponding author: X.-F. Liang

E-mail: xufang_liang@hotmail.com

Genet. Mol. Res. 13 (1): 546-558 (2014)

Received August 20, 2013

Accepted November 27, 2013

Published January 22, 2014

DOI http://dx.doi.org/10.4238/2014.January.22.1

\begin{abstract}
The mandarin fish is a popular fresh water food fish in China. Fifty-three polymorphic microsatellite markers were isolated through construction of an enriched library of genomic DNA of Siniperca chuatsi (Percichthyidae). We found 2 to 7 alleles per locus. The observed and expected heterozygosity values varied from 0.059 to 1.000 and from 0.305 to 0.818 , respectively. The polymorphic information content value varied from 0.255 to 0.782 . Twelve microsatellite loci deviated significantly from Hardy-Weinberg equilibrium after Bonferroni's correction. These markers were evaluated in five species of sinipercine fish; $98 \%$ of the 265 locus/taxon combinations tested gave crossamplification. Eight polymorphic microsatellite markers were randomly selected for genetic characterization of three $S$. chuatsi populations. The Ganjiang River and Yuanjiang River populations had moderate levels of genetic diversity, while the Mudanjiang River population had a relatively low level genetic diversity. Genetic distance-based cluster analysis showed clustering of the Ganjiang River and Yuanjiang River
\end{abstract}


populations in a single group and the Mudanjiang River population in a separate group. Based on these results, we suggest that $S$. chuatsi from the Yangtze River watershed are distinct from the Mudanjiang River population. These SSR markers will be useful for diversity, mapping and marker assisted studies of $S$. chuatsi and other sinipercine fishes.

Key words: Siniperca chuatsi; Microsatellite markers; Cross-amplification; Population genetics

\section{INTRODUCTION}

The mandarin fish Siniperca chuatsi (Basilewsky) is an endemic freshwater fish species in East Asian countries, specifically distributed in the Yangtze River drainage in China (Liang, 1996). As one of the commercially important and peculiar freshwater fish species in China, its status now has increasingly risen in lake and reservoir fisheries (Liu and Cui, 1998). Interests in stocking and artificial breeding of this fish are developing (Xie et al., 2003). Farmed production of $S$. chuatsi from China was reported to be almost 252,622 tonnes by 2010 (FAO). However, because of the damming of rivers, water pollution and overfishing, its natural resources have been exhausted. Thus, the genetic characterization of the $S$. chuatsi wild population is urgently needed, especially in the main distribution areas (such as the Yangtze River drainage and the Heilongjiang River drainage), which has not been done for this species so far.

Genetic tools are useful to improve fishery management and exploit new fishery sources (Zhang et al., 2006). Microsatellites (also known as simple sequence repeats, SSRs) have become a useful marker system in population genetic analysis, genetic mapping and marker-assisted selection (MAS) of many kinds of fish species because of their co-dominant nature, high allelic polymorphism and high reproducibility (Hamada et al., 1982; Walter and Epperson, 2001). In previous studies, Fang et al. (2005) first developed the random amplified polymorphic DNA markers in S. chuatsi, and several genomic SSR DNA markers were gradually isolated from this species (Zhang et al., 2006; Kuang et al., 2009; Liu et al., 2011). These SSR markers have provided a sufficient tool to evaluate wild and cultured genetic resources in this species, but they are still lacking for SSR-based mapping studies and further MAS studies.

To aid in the investigation of the population genetic structure and MAS of S. chuatsi, it is important to isolate more polymorphic molecular markers. In this study, 53 polymorphic SSR markers for $S$. chuatsi were isolated and cross-amplified in five species of sinipercine fishes. Meanwhile, eight polymorphic SSR markers developed in this study were used to carry out the genetic characterization of three wild populations from two main distribution areas.

\section{MATERIAL AND METHODS}

\section{Sample collection and DNA extraction}

A total of 83 S. chuatsi individuals were sampled from three local populations in China: two populations from the Yangtze River drainage, Ganjiang River (GJ, N = 30) and Yuanjiang River (YJ, N = 29), and one population from Mudanjiang River, a tributary of Heilongjiang River drainage (MDJ, $\mathrm{N}=24$ ). Total genomic DNA was extracted from fin clips using the TIANamp Genomic DNA kit (Tiangen, Beijing, China) following manufacturer instructions. The DNA was adjusted to $100 \mathrm{ng} / \mu \mathrm{L}$ and stored at $-20^{\circ} \mathrm{C}$. 


\section{Development of microsatellite markers}

SSRs were isolated using a hybridization-based capture method, following the protocol described by Zane et al. (2002). Briefly, high-quality genomic DNA was fragmented using the restriction enzyme MseI (BioLabs, USA). The fragmented DNAs were ligated to specific adapters (5'-GACGATGAGTCCTGAG-3' and 5'-TACTCAGGACTCAT-3'). The PCR products were size selected to preferentially obtain small fragments (300-1000 bp), which were hybridized with 3'-biotinylated oligoprobes for $(\mathrm{CA} / \mathrm{GT})_{14},(\mathrm{CCT} / \mathrm{GGA})_{15}$ and (GATA/CTAT) repeats. The enriched DNAs were cloned into the pGEM-T vector (Promega, USA) and then transformed into Escherichia coli DH5a competent cells (Promega). White colonies were randomly picked from the primary transformation plates, identified by PCR using MseI-N and M13 primers, and the isolated Plasmid DNA was then sequenced using an ABI 3730 Genetic Analyzer (Applied Biosystems, USA). The SSRs were screened using the SSRHUNTER program ( $\mathrm{Li}$ and Wan, 2005). For all types of SSRs, a minimum length criterion of $12 \mathrm{bp}$ was selected, and only perfect SSRs were considered. Primers flanking SSRs were designed using the PRIMER PREMIER 5.0 program (PREMIER Biosoft International, USA).

\section{Amplification and characterization of microsatellite loci}

PCR amplifications were performed in a $25-\mu \mathrm{L}$ reaction volume comprising about 50 ng genomic DNA, $2.5 \mu \mathrm{L}$ 10X PCR buffer, $1.0-3.0 \mathrm{mM} \mathrm{MgCl}, 0.4 \mu \mathrm{M}$ of each primer, $50 \mu \mathrm{M}$ of each dNTP and 1.0 U EasyTaq ${ }^{\mathrm{TM}}$ DNA polymerase (Transgen, China). PCR amplifications were conducted under the following conditions: $4 \mathrm{~min}$ at $94^{\circ} \mathrm{C}$ followed by 30 cycles of 30 $\mathrm{s}$ at $94^{\circ} \mathrm{C}, 45 \mathrm{~s}$ at a primer-specific annealing temperature (Table 1 ), and $30 \mathrm{~s}$ at $72^{\circ} \mathrm{C}$, with a final extension step of $10 \mathrm{~min}$ at $72^{\circ} \mathrm{C}$. The PCR products were separated on a sequencing gel containing $8 \%$ polyacrylamide and visualized using silver staining. Denatured pBR322 DNA/ Msp I molecular weight marker (Tiangen) was used as size standard to identify alleles. Screening of all the above SSR loci was carried out with 11 to 12 individuals from each of the three S. chuatsi populations: $\mathrm{GJ}(\mathrm{N}=12), \mathrm{YJ}(\mathrm{N}=11)$, $\mathrm{MDJ}(\mathrm{N}=11)$.

Cross-species amplification of the above-developed polymorphic SSR loci was tested in five species of sinipercine fishes: Siniperca scherzeri, Siniperca kneri, Siniperca undulata, Siniperca obscura, and Coreoperca whiteheadi. Two individuals of each species were analyzed. The same PCR conditions were used as described above. Amplification products were visualized on $1.5 \%$ agarose gels, and fragments were sized by comparison with a 2000 DNA marker (Transgen). Primer pairs that amplified fragments with similar sizes as those observed in source species were considered a successful cross-species amplification. Next, a total of 83 adult $S$. chuatsi individuals from three populations were genotyped using the eight polymorphic SSR loci developed in this study.

\section{Data analysis}

The number of alleles per locus $\left(N_{\mathrm{A}}\right)$, observed heterozygosity $\left(H_{\mathrm{O}}\right)$ and expected heterozygosity $\left(H_{\mathrm{E}}\right)$ for each population at each locus and fixation index $\left(F_{\mathrm{IS}}\right)$ were calculated directly from SSR phenotypes using the Genepop 3.1 program (Raymond and Rousset, 1995). Departures from Hardy-Weinberg equilibrium (HWE) and linkage disequilibrium between pairs of loci were also estimated by Genepop 3.1. All results were adjusted for multiple simul- 
taneous comparisons using a sequential Bonferroni correction (Holm, 1979). The presence of null alleles was tested at a 95\% confidence interval using MICRO-CHECKER, version 2.2.3 (Van Oosterhout et al., 2004). The Arlequin 3.0 program (Excoffier et al., 2005) was employed to calculate pairwise $F_{\mathrm{ST}}$ values and test their significance by bootstrapping analysis (1000 replicates) for evaluating genetic differentiation between populations. The genetic distance between the populations was calculated using chord distance $D_{C E}$ with Gendist (Cavalli-Sforza and Edwards, 1967), included in Phylip 3.5 (Felsenstein and Churchill, 1995). The distance matrices were then used to construct a UPGMA dendrogram with neighbor in Phylip 3.5.

\section{RESULTS}

\section{Polymorphic microsatellite marker development and cross-amplification}

A microsatellite-enriched library was constructed from the genomic DNA of S. chuatsi. A total of 450 putative recombinant clones were picked from the enriched library, sequenced, and analyzed for presence of SSRs. Sequence analysis revealed that 96 clones $(21.33 \%)$ were redundant clones. Of the remaining 354 unique clones (78.67\%), 324 (91.53\% of the unique clones) were found to harbor SSRs (GenBank accession Nos. JN602684-JN602722, JQ723523-JQ723598, JQ804524-JQ804670, and JX027215-JX027276), and 144 could be finally used for primer design. Sequence analysis of all the SSR-containing clones indicated that dinucleotide SSRs were found to be more frequent (87\%) than trinucleotide SSRs (5\%). Furthermore, a small number (7\%) of tetra-/penta-/hexanucleotide SSRs were also identified in the library. Among the dinucleotide SSRs, the AC/TG class of repeat motif was the most frequent ( $88.5 \%$ of total dinucleotide microsatellites), followed by the GA/CT class $(6.3 \%)$.

In this research, among the successfully amplified primer pairs, 53 loci $(36.8 \%$ of the designed primers) showed polymorphism in the 34 individuals (Table 1), while the others were monomorphic. The $N_{\mathrm{A}}, H_{\mathrm{O}}$ and $H_{\mathrm{E}}$ per locus in 34 individuals ranged from 2 to $7,0.059$ to 1.000 , and 0.305 to 0.818 , respectively. Polymorphic information content varied from 0.255 to 0.782 . Twelve SSR loci deviated significantly from HWE $(\mathrm{P}<0.00097)$ after Bonferroni's correction (Table 1). Analysis with MICROCHECKER indicated the possible occurrence of null alleles at seven of the SSRs (CB02, CB54, PY01, PY05, PY08, PY25, and MDJ477).

Overall, a high level of cross-species amplification was observed across the five species (Table 2). All 53 polymorphic loci (100\%) were successfully amplified in S. scherzeri, $S$. kneri, and S. undulata, 51 (96.2\%) in S. obscura, and 50 (94.3\%) in C. whiteheadi.

\section{Population genetic variation}

A total of 83 adult $S$. chuatsi individuals collected from three local populations in China were genotyped using the eight SSR loci developed in this study. Of the eight SSR loci screened, six were found to be highly polymorphic, while two loci, MDJ847 and MDJ825, were found to be weakly polymorphic (Table 3) in the GJ and YJ populations. While in the MDJ population, only one locus (PY45) was found to be highly polymorphic, five loci weakly polymorphic, one locus (PY27) monomorphic, and one locus (CD273) had no PCR products. In 83 individuals from the three populations, 91 alleles were observed and $N_{\mathrm{A}}$ was 3.77 (ranging from 2.43 to 4.63 ). The average number of alleles per population per locus varied from 3 to 8 . Among the three populations, the lowest mean number of alleles per locus (2.43) was observed in the MDJ population, while the highest (4.63) was found in the GJ population. 


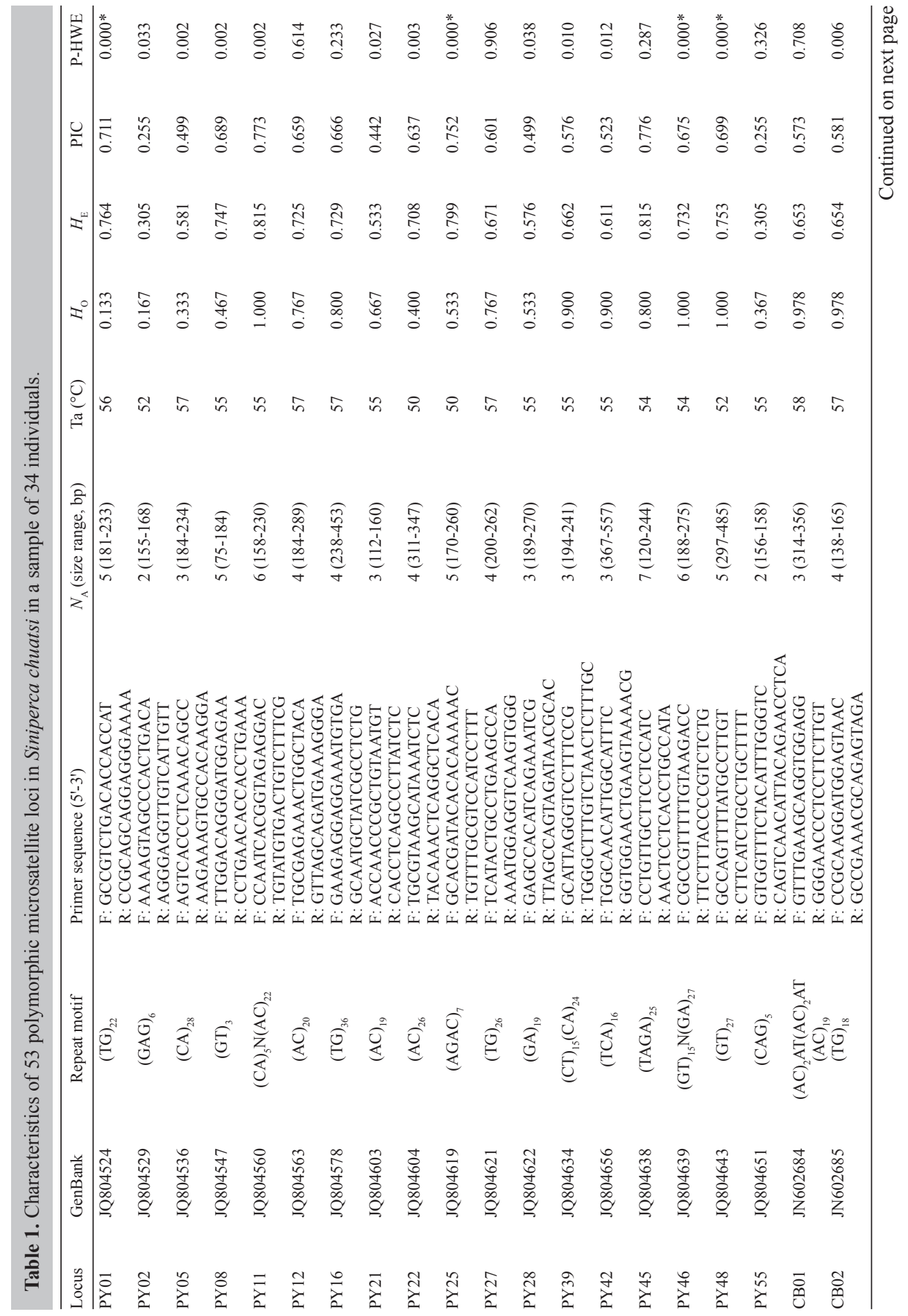


Microsatellite markers and mandarin fish genetic diversity

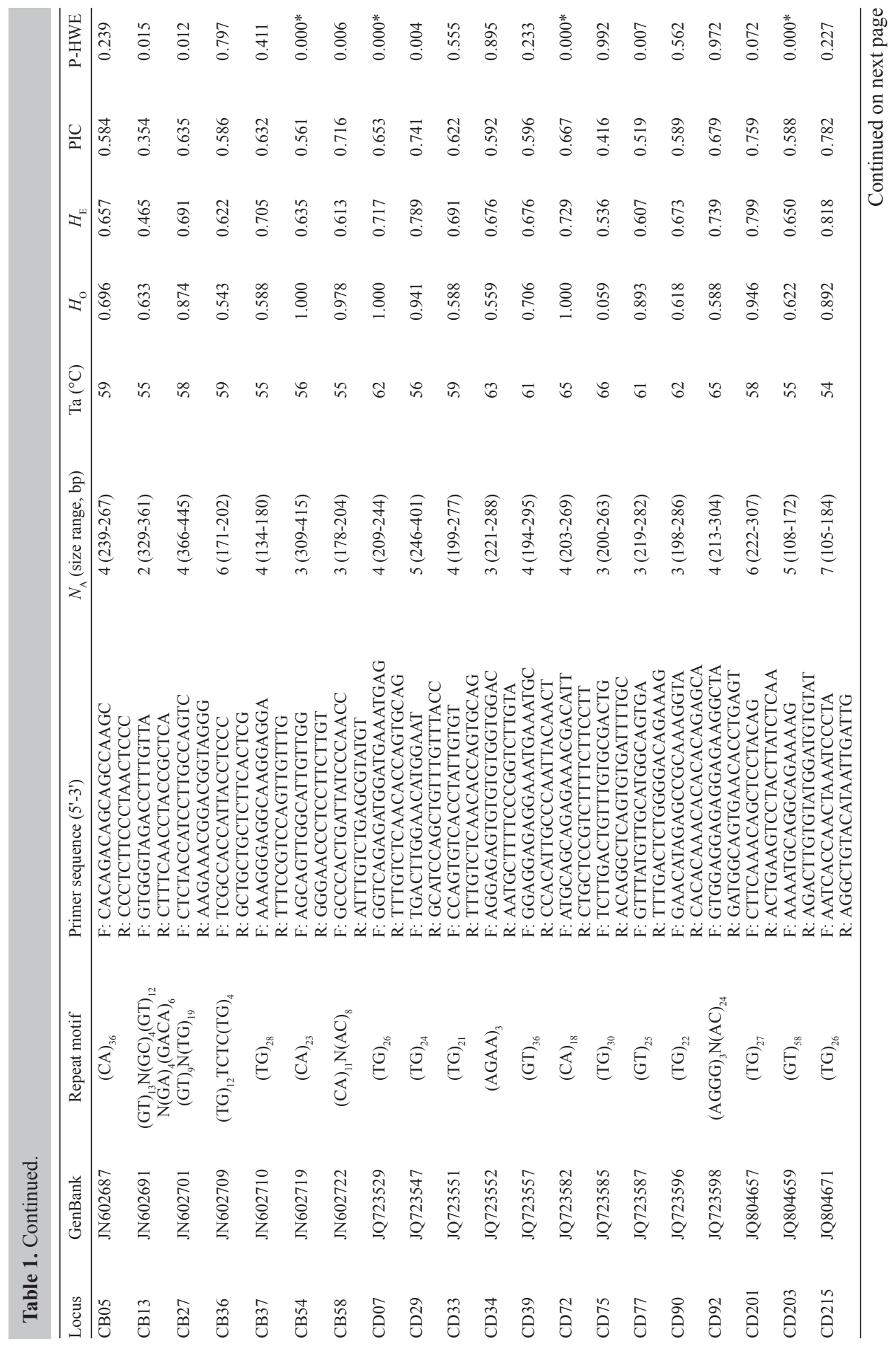




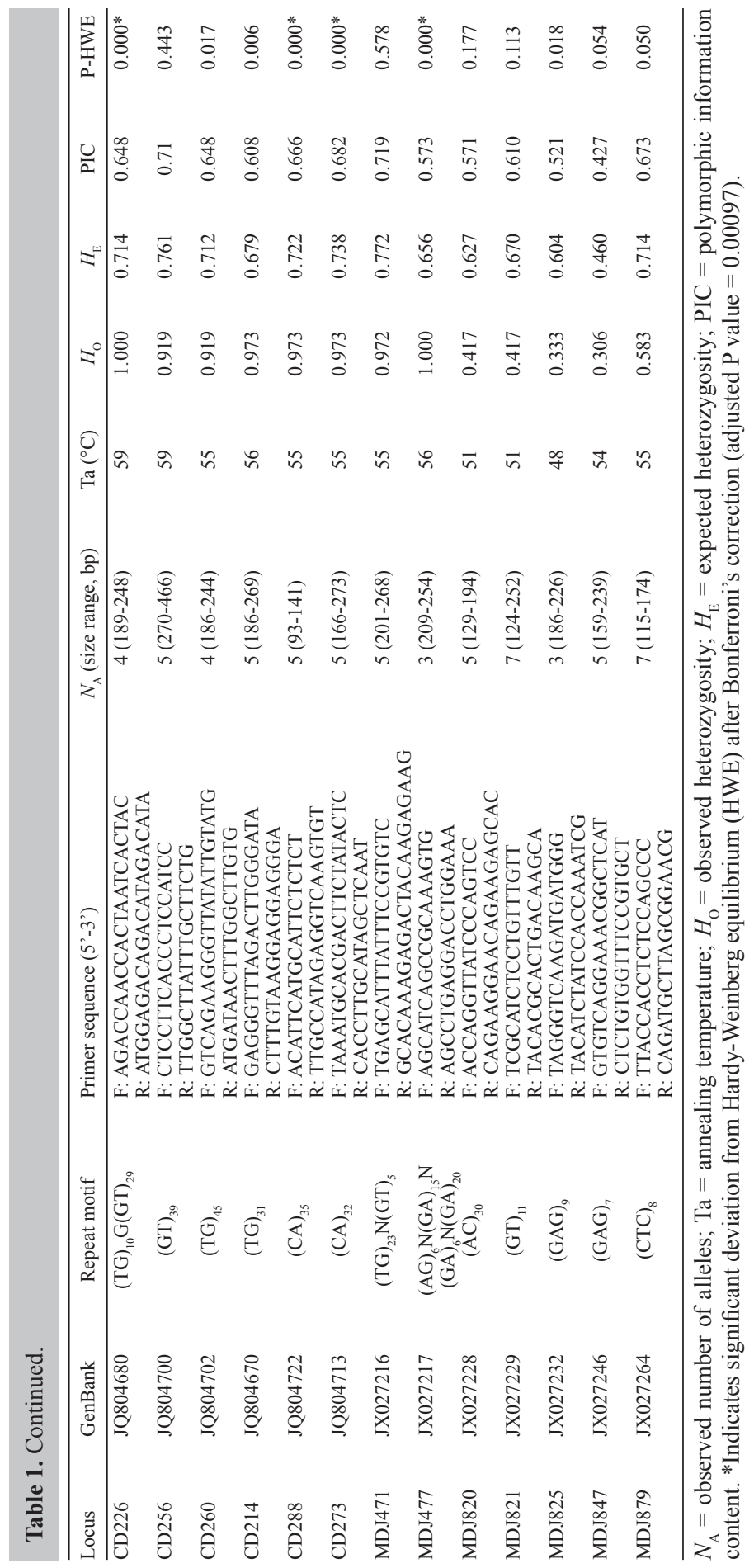




\begin{tabular}{|c|c|c|c|c|c|}
\hline \multirow[t]{2}{*}{ Locus } & \multicolumn{5}{|c|}{ Species } \\
\hline & S. scherzeri & S. kneri & S. obscura & S. undulata & C. whiteheadi \\
\hline CB01 & 58.5 & 58.5 & 58.5 & 58.5 & 58.5 \\
\hline CB02 & 56.5 & 56.5 & 56.5 & 56.5 & 56.5 \\
\hline CB05 & 58.5 & 58.5 & 58.5 & 58.5 & 58.5 \\
\hline CB13 & 55 & 55 & 55 & - & 55 \\
\hline $\mathrm{CB} 27$ & 58.5 & 58.5 & 58.5 & 58.5 & 58.5 \\
\hline CB36 & 58.5 & 58.5 & 58.5 & 58.5 & 58.5 \\
\hline CB37 & 55 & 55 & 55 & 55 & 55 \\
\hline CB54 & 56.5 & 56.5 & 56.5 & 56.5 & 56.5 \\
\hline CB58 & 55 & 55 & 55 & 55 & 55 \\
\hline CD07 & 63 & 63 & 63 & 63 & 63 \\
\hline CD29 & 56.5 & 56.5 & 56.5 & 56.5 & 56.5 \\
\hline CD33 & 58.5 & 58.5 & 58.5 & 58.5 & 58.5 \\
\hline CD34 & 63 & 63 & 63 & 63 & 63 \\
\hline CD39 & 63 & 63 & 63 & 63 & 63 \\
\hline CD72 & 63 & 63 & 63 & 63 & 63 \\
\hline CD75 & 63 & 63 & 63 & 63 & 63 \\
\hline CD77 & 63 & 63 & 63 & 63 & 63 \\
\hline CD90 & 63 & 63 & 63 & 63 & 63 \\
\hline CD92 & 63 & 63 & 63 & 63 & 63 \\
\hline CD201 & 58.5 & 58.5 & 58.5 & 58.5 & 58.5 \\
\hline CD203 & 55 & 55 & 55 & 55 & 55 \\
\hline CD214 & 56.5 & 56.5 & 56.5 & 56.5 & 56.5 \\
\hline CD215 & 55 & 55 & 55 & 55 & 55 \\
\hline CD226 & 58.5 & 58.5 & 58.5 & 58.5 & 58.5 \\
\hline CD256 & 58.5 & 58.5 & 58.5 & 58.5 & 58.5 \\
\hline CD260 & 55 & 55 & 55 & 55 & 55 \\
\hline CD273 & 55 & 55 & 55 & 55 & - \\
\hline CD288 & 55 & 55 & 55 & 55 & 55 \\
\hline MDJ471 & 55 & 55 & 55 & 55 & 55 \\
\hline MDJ477 & 56.5 & 56.5 & 56.5 & 56.5 & - \\
\hline MDJ820 & 50 & 50 & 50 & 50 & 50 \\
\hline MDJ821 & 55 & 55 & 55 & 55 & - \\
\hline MDJ879 & 50 & 50 & 50 & 50 & 50 \\
\hline MDJ847 & 55 & 55 & 55 & 55 & 55 \\
\hline PY01 & 56.5 & 56.5 & 56.5 & 56.5 & 56.5 \\
\hline PY02 & 50 & 50 & 50 & 50 & 50 \\
\hline PY05 & 56.5 & 56.5 & 56.5 & 56.5 & 56.5 \\
\hline PY08 & 55 & 55 & 55 & 55 & 55 \\
\hline PY11 & 55 & 55 & 55 & 55 & 55 \\
\hline PY12 & 56.5 & 56.5 & 56.5 & 56.5 & 56.5 \\
\hline PY16 & 56.5 & 56.5 & 56.5 & 56.5 & 56.5 \\
\hline PY21 & 55 & 55 & 55 & 55 & 55 \\
\hline PY22 & 50 & 50 & 50 & 50 & 50 \\
\hline PY25 & 50 & 50 & 50 & 50 & 50 \\
\hline PY27 & 56.5 & 56.5 & 56.5 & 56.5 & 56.5 \\
\hline PY28 & 55 & 55 & 55 & - & 55 \\
\hline PY39 & 55 & 55 & 55 & 55 & 55 \\
\hline PY42 & 55 & 55 & 55 & 55 & 55 \\
\hline PY45 & 55 & 55 & 55 & 55 & 55 \\
\hline PY46 & 55 & 55 & 55 & 55 & 55 \\
\hline PY48 & 50 & 50 & 50 & 50 & 50 \\
\hline PY55 & 55 & 55 & 55 & 55 & 55 \\
\hline
\end{tabular}

The annealing temperature for each locus was shown. Unsuccessful amplification of PCR products for each locus is denoted by '-'.

$H_{\mathrm{E}}$ ranged from 0.44 to 0.63 . The lowest $H_{\mathrm{E}}$ was in the MDJ population (0.44), and the highest in the GJ population (0.63). The lowest $H_{\mathrm{O}}$ was in the MDJ population (0.57), whereas the highest in the YJ population (0.76) (Table 3). $H_{\mathrm{O}}$ of all the populations at loci 
CD39, CD215, CD273, PY16, PY27, and PY45 was higher than $H_{\mathrm{E}}$, while $H_{\mathrm{O}}$ at loci MDJ847 and MDJ825 was lower than that expected.

\begin{tabular}{|c|c|c|c|c|}
\hline \multirow[t]{2}{*}{ Microsatellite locus } & \multirow[t]{2}{*}{ Parameters } & \multicolumn{3}{|c|}{ Population } \\
\hline & & GJ $(\mathrm{N}=30)$ & $\mathrm{YJ}(\mathrm{N}=29)$ & MDJ $(\mathrm{N}=24)$ \\
\hline \multirow[t]{5}{*}{$\overline{\mathrm{CD} 39}$} & $N_{\mathrm{A}}$ & 4 & 4 & 2 \\
\hline & $H_{\mathrm{O}}^{\mathrm{A}} / H_{\mathrm{E}}$ & $1.00 / 0.70$ & $1.00 / 0.73$ & $1.00 / 0.51$ \\
\hline & PIC & 0.63 & 0.66 & 0.38 \\
\hline & $\mathrm{P}_{\mathrm{HW}}$ & $* *$ & $* *$ & $* *$ \\
\hline & $F_{\mathrm{IS}}^{\mathrm{HW}}$ & -0.32 & -0.32 & -1.00 \\
\hline \multirow[t]{5}{*}{$\mathrm{CD} 215$} & $N_{\mathrm{A}}$ & 8 & 4 & 3 \\
\hline & $H_{\mathrm{O}}^{\mathrm{A}} / H_{\mathrm{F}}$ & $1.00 / 0.86$ & $1.00 / 0.75$ & $1.00 / 0.54$ \\
\hline & PIC & 0.83 & 0.69 & 0.43 \\
\hline & $\mathrm{P}_{\mathrm{HW}}$ & $*$ & $* *$ & $* *$ \\
\hline & $F_{\text {IS }}$ & -0.13 & -0.32 & -0.49 \\
\hline \multirow[t]{5}{*}{$\mathrm{CD} 273$} & $N_{4}$ & 5 & 5 & - \\
\hline & $H_{\mathrm{O}}^{\mathrm{A}} / H_{\mathrm{E}}$ & $0.87 / 0.78$ & $0.90 / 0.75$ & - \\
\hline & PIC & 0.73 & 0.69 & - \\
\hline & $\mathrm{P}_{\mathrm{HW}}$ & n.s. & n.s. & - \\
\hline & $F_{\mathrm{IS}}$ & -0.06 & -0.13 & - \\
\hline \multirow{5}{*}{ MDJ847 } & $N_{\mathrm{A}}$ & 3 & 2 & 2 \\
\hline & $H_{\mathrm{O}}^{\mathrm{A}} / H_{\mathrm{E}}$ & $0.07 / 0.35$ & $0.14 / 0.29$ & $0.25 / 0.38$ \\
\hline & $\mathrm{PIC}^{\mathrm{E}}$ & 0.31 & 0.24 & 0.30 \\
\hline & $\mathrm{P}_{\mathrm{HW}}$ & $* *$ & $*$ & n.s. \\
\hline & $F_{\text {IS }}$ & 0.84 & 0.54 & 0.36 \\
\hline \multirow{5}{*}{ MDJ825 } & $N_{\mathrm{A}}$ & 3 & 3 & 2 \\
\hline & $H_{\mathrm{O}}^{\mathrm{A}} / H_{\mathrm{E}}$ & $0.07 / 0.21$ & $0.10 / 0.13$ & $0.17 / 0.34$ \\
\hline & PIC & 0.19 & 0.13 & 0.28 \\
\hline & $\mathrm{P}_{\text {нш }}$ & ** & n.s. & n.s. \\
\hline & $F_{\mathrm{IS}}$ & 0.35 & 0.00 & 0.52 \\
\hline \multirow[t]{5}{*}{ PY16 } & $N_{\mathrm{A}}$ & 3 & 5 & 2 \\
\hline & $H_{\mathrm{O}}^{\mathrm{A}} / H_{\mathrm{F}}$ & $1.00 / 0.63$ & $1.00 / 0.74$ & $1.00 / 0.51$ \\
\hline & $\mathrm{PIC}^{\mathrm{E}}$ & 0.55 & 0.68 & 0.38 \\
\hline & $\mathrm{P}_{\mathrm{HW}}$ & $* *$ & $* *$ & $* *$ \\
\hline & $F_{\mathrm{IS}}$ & -0.49 & -0.19 & -1.00 \\
\hline \multirow[t]{5}{*}{ PY27 } & $N_{\mathrm{A}}^{\mathrm{S}}$ & 5 & 4 & 1 \\
\hline & $H_{\mathrm{O}}^{\mathrm{A}} / H_{\mathrm{E}}$ & $1.00 / 0.70$ & $1.00 / 0.71$ & $0 / 0$ \\
\hline & PIC & 0.64 & 0.64 & 0.00 \\
\hline & $\mathrm{P}_{\mathrm{HW}}$ & $* *$ & ** & - \\
\hline & $F_{\mathrm{IS}}$ & -0.24 & -0.32 & 0.00 \\
\hline \multirow[t]{5}{*}{ PY45 } & $N_{\mathrm{A}}$ & 6 & 6 & 5 \\
\hline & $H_{\mathrm{O}}^{\mathrm{A}} / H_{\mathrm{E}}$ & $0.93 / 0.83$ & $0.93 / 0.83$ & $0.58 / 0.78$ \\
\hline & $\mathrm{PIC}^{\mathrm{E}}$ & 0.79 & v0.79 & 0.73 \\
\hline & $\mathrm{P}_{\mathrm{HW}}$ & n.s. & n.s. & n.s. \\
\hline & $F_{\text {IS }}$ & -0.11 & -0.12 & 0.17 \\
\hline \multirow{4}{*}{ Mean } & $N_{\mathrm{A}}$ & 4.63 & 4.25 & 2.43 \\
\hline & $H_{\mathrm{O}}^{\mathrm{A}} / H_{\mathrm{E}}$ & $0.74 / 0.63$ & $0.76 / 0.62$ & $0.57 / 0.44$ \\
\hline & PIC & 0.57 & 0.58 & 0.36 \\
\hline & $F_{\text {IS }}$ & -0.16 & -0.60 & -1.44 \\
\hline
\end{tabular}

GJ = Ganjiang River; YJ = Yuanjiang River; MDJ = Mudanjiang River; $N_{\mathrm{A}}=$ number of alleles; $H_{\mathrm{O}}=$ observed heterozygosity; $H_{\mathrm{E}}=$ expected heterozygosity; PIC = polymorphic information content; $\mathrm{P}_{\mathrm{HW}}=$ Hardy-Weinberg probability test $(* \mathrm{P}<0.05, * * \mathrm{P}<0.01$, n.s. $=$ non-significant $) ; F_{\text {IS }}=$ fixation indices. Unsuccessful amplification of PCR products for each locus is denoted by '-'.

\section{HWE test}

Of the 24 HWE tests, 14 were significant (Table 3). The GJ, YJ and MDJ populations had six, five and three microsatellite loci, respectively, which departed from HWE. On the 
basis of average $F_{\text {IS }}$ values, it can be seen that the pattern of heterozygote excess was most pronounced in all three populations, indicating the excess of heterozygosity within populations in accordance with significant deviations from HWE $(\mathrm{P}<0.05)$. However, the deviations of the MDJ847 and MDJ825 loci from HWE were also detected in some of the populations due to deficiency in heterozygosity in all the samples.

\section{Population genetic differentiation and relationships between populations}

All pairwise $F_{\mathrm{ST}}$ statistics estimated were significant $(\mathrm{P}<0.01)$, suggesting that all three populations were significantly different from each other (Table 4). The greatest divergence was between the YJ and MDJ populations $\left(F_{\mathrm{ST}}=0.3711\right)$, while the least divergence was between the YJ and GJ populations $\left(F_{\mathrm{ST}}=0.2519\right)$.

On the basis of genetic distance, the UPGMA dendrogram displayed two major clusters (Figure 1). Cluster A contained the YJ and GJ populations. The remaining population formed cluster B.

Table 4. Pairwise $F_{\mathrm{ST}}$ values (below the diagonal) and $\mathrm{D}_{\mathrm{CE}}$ distance (above the diagonal) between three Siniperca
chuatsi populations in China based on eight microsatellite loci.
\begin{tabular}{lcccr}
\hline Populations & GJ & YJ & MDJ \\
\hline GJ & - & 0.7761 & 1.1449 \\
YJ & 0.2519 & - & 1.0862 \\
MDJ & 0.3709 & 0.3711 & - \\
\hline
\end{tabular}

For population abbreviations, see Table 3 .

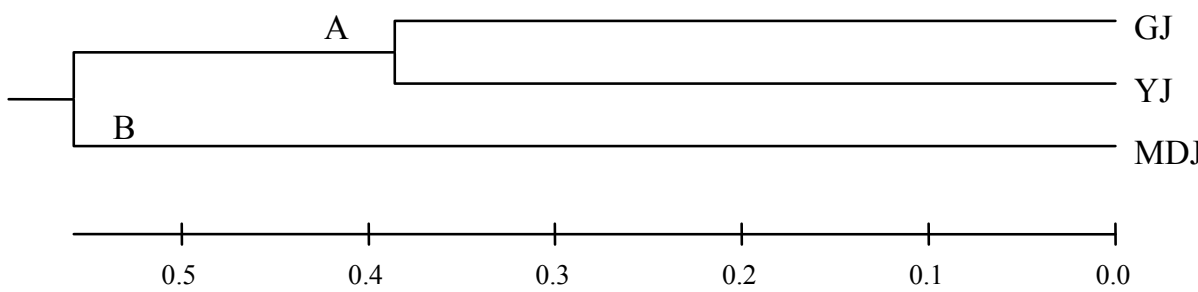

Figure 1. UPGMA dendrogram of Siniperca chuatsi populations based on a matrix of $D_{C E}$ distance. Three populations were clustered into in A and B. GJ = Ganjiang River; YJ = Yuanjiang River; MDJ = Mudanjiang River.

\section{DISCUSSION}

A number of SSR markers have been isolated in S. chuatsi (Zhang et al., 2006; Kuang et al., 2009; Liu et al., 2011; Qu et al., 2012) and provide a sufficient tool to evaluate its genetic resources. However, they are still lacking for SSR-based mapping studies and further MAS studies, which have not been conducted for this species so far. Fifty-three polymorphic SSR markers for $S$. chuatsi were isolated in this study, where $36.8 \%$ of the designed primers were found to be polymorphic, comparable to a value of $37.5 \%$ in two previous studies (Zhang et al., 2006; Kuang et al., 2009) but lower than 60.5\% reported by Liu et al. (2011). This large difference may have been caused by the different sampling strategy. Although 11 of 53 loci 
showed significant deviation from HWE after Bonferroni's correction with the plausible occurrence of a null allele at four of these loci (Miao et al., 2011), these markers can still be used for population genetic studies if analytical methods are used to correct for null alleles (Park et al., 2012). S. chuatsi possesses 24 haploid chromosomes (Dong et al., 2008), and some of the microsatellites undoubtedly are linked. Determination of linkage will require further mapping studies. The high levels of polymorphism and heterozygosity exhibited at these loci suggest that these loci should provide a valuable tool for population studies, mapping studies and MAS of $S$. chuatsi.

A high level of cross-species amplification was observed across five species. These results were expected because of the taxonomical relationships of the families (Liu, 1993; Qu et al., 2012). S. scherzeri, S. kneri, S. undulata, and S. obscura are closely related to S. chuatsi, and all species belong to Siniperca, whereas $C$. whiteheadi is from Coreoperca, which is a sister genus to Siniperca. The high level of cross-species amplification demonstrated here indicates the potential usefulness of the developed markers for a broader range of evolutionary, conservation and management studies in sinipercine fishes.

Eight polymorphic SSR markers developed in this study were successfully applied to obtain preliminary population genetic parameters for $83 \mathrm{~S}$. chuatsi specimens from three populations. Except the MDJ population, the population genetic parameters were similar to the results of a previous study using ten SSR markers to compare genetic diversity among seven populations (Wu et al., 2010). Eight SSR loci were randomly selected in this study, so all the isolated markers may provide a valuable tool for further studies in S. chuatsi.

Compared to the GJ and YJ populations, the MDJ population has a relatively low genetic diversity, suggesting that genetic characteristics of $S$. chuatsi in the Yangtze River drainage are distinct compared to the Heilongjiang River drainage. It may result from inbreeding in the MDJ population during artificial propagation and neglecting the genetic diversities while carrying out artificial releasing program.

All populations deviated significantly from HWE at most of the SSR loci in which heterozygote excess was apparent. It revealed inbreeding and the bottleneck effect as the main limitations to genetic differentiation between the three populations. However, the three populations at two loci (MDJ847, MDJ825) showed deviation from HWE without heterozygosity excess at either locus, which could be explained by an excess of certain genotypes. Selection, population mixing and nonrandom mating may be the factors driving deviations from HWE (Sun et al., 2011). There were 15 private alleles found in three populations (data not shown). These private alleles could be used as population-specific markers for selection of a candidate stock in controlled breeding programs, even though more samples from each population would be needed to confirm these results (An et al., 2009; Zhuo et al., 2012).

Clustering order reflects relationships between populations. In this research, the GJ and YJ populations share the highest genetic identity among the three populations, indicating the closest genetic relationship. Populations GJ and MDJ showed the lowest genetic identity and their genetic relationship was the farthest. The population structure of freshwater organisms is primarily dependent on the distribution of river systems, as previously reported (Nagarajan et al., 2006; Zhuo et al., 2012). Genetic differentiation is primarily dependent on geographical isolation.

In conclusion, fifty-three polymorphic SSR markers for $S$. chuatsi were isolated and cross-amplified in five species of sinipercine fishes in this study. Meanwhile, the genetic characterization of three S. chuatsi populations was performed using eight polymorphic SSR 
markers developed in this study. These SSR markers will be useful for further studies of the diversity, mapping and MAS of $S$. chuatsi and other sinipercine fishes.

\section{ACKNOWLEDGMENTS}

Research supported by the National Natural Science Foundation of China (\#31272641 and \#31172420), the National Basic Research Program of China (\#2014CB138601), the Key Projects in the National Science \& Technology Pillar Program during the Twelfth Five-year Plan Period (\#2012BAD25B04), the Fundamental Research Funds for the Central Universities (\#2011PY030, \#2013PY072) and Huazhong Agricultural University Scientific \& Technological Self-Innovation Foundation (\#2012SC24).

\section{REFERENCES}

An HS, Lee YG, Park JY and Lee C (2009). Genetic characterization of four East Asian giant scallop (Mizuhopecten yessoensis) populations using microsatellite markers. Aquacult. Res. 40: 619-624.

Cavalli-Sforza LL and Edwards AW (1967). Phylogenetic analysis. Models and estimation procedures. Am. J. Hum. Genet. 19: 233-257.

Dong C, Weng S, Shi X, Xu X, et al. (2008). Development of a mandarin fish Siniperca chuatsi fry cell line suitable for the study of infectious spleen and kidney necrosis virus (ISKNV). Virus Res. 135: 273-281.

Excoffier L, Laval G and Schneider S (2005). Arlequin (version 3.0): an integrated software package for population genetics data analysis. Evol. Bioinform. Online 1: 47-50.

Fang ZQ, Chen J, Zheng WB, Wu YY, et al. (2005). RAPD analysis of wild population and cultivated population in Siniperca chuatsi Basilewsky. J. Dalian Fish. Uni. 20: 16.

Felsenstein J and Churchill GA (1995). A hidden markov model approach to variation among sites in rate of evolution. Mol. Biol. Evol. 13: 93-104.

Hamada H, Petrino MG and Kakunaga T (1982). A novel repeated element with Z-DNA-forming potential is widely found in evolutionarily diverse eukaryotic genomes. Proc. Natl. Acad. Sci. U. S. A. 79: 6465-6469.

Holm S (1979). A simple sequentially rejective multiple test procedure. Scand. J. Stat. 6: 65-70.

Kuang G, Lu S, Zheng S and Wu Q (2009). Isolation and evaluation of 18 microsatellite markers in Siniperca chuatsi (Basilewsky). Mol. Ecol. Resour. 9: 1473-1475.

Li Q and Wan JM (2005). SSRHunter: development of a local searching software for SSR sites. Yi Chuan 27: 808-810.

Liang XF (1996). Study on Mandarin Fish and its Culture Home and Abroad. Fish. Sci. Tech. Inf. 23: 13-17.

Liu HZ (1993). Studies on Skeleton Anatomy and Phylogeny of the Sinipericine Fishes. Ph.D. Dissertation, Institute of Hydrobiology, Chinese Academy of Sciences, Wuhan.

Liu J and Cui Y (1998). Food consumption and growth of two piscivorous fishes, the mandarin fish and the Chinese snakehead. J. Fish Biol. 53: 1071-1083.

Liu X, Luo W, Zeng C, Wang W, et al. (2011). Isolation of New 40 Microsatellite Markers in Mandarin Fish (Siniperca chuatsi). Int. J. Mol. Sci. 12: 4180-4189.

Miao GD, Liu HW, Ma HY, Chen SL, et al. (2011). Isolation and characterization of 54 polymorphic microsatellite loci for half-smooth Tongue Sole, Cynoglossus semilaevis Issue. J. World Aquacul. Soc. 42: 462-467.

Nagarajan M, Haniffa MA, Gopalakrishnan A, Basheer VS, et al. (2006). Genetic variability of Channa punctatus populations using randomly amplified polymorphic DNA. Aquacult. Res. 37: 1151-1155.

Park M, Kim KS and Lee JH (2012). Isolation and characterization of eight microsatellite loci from Lycorma delicatula (White) (Hemiptera: Fulgoridae) for population genetic analysis in Korea. Mol. Biol. Rep. 39: 5637-5641.

Qu CM, Liang XF, Huang W and Cao L (2012). Isolation and characterization of 46 novel polymorphic EST-SSR markers in two sinipercine fishes (Siniperca) and cross-species amplification. Int. J. Mol. Sci. 13: 9534-9544.

Raymond M and Rousset F (1995). GENEPOP (Version 1.2): Population Genetics Software for Exact Tests and Ecumenism. J. Hered. 86: 248-249.

Sun DQ, Shi G, Liu XZ, Wang RX, et al. (2011). Genetic diversity and population structure of the marbled rockfish, Sebastiscus marmoratus, revealed by SSR markers. J. Genet. 90: e21-e24.

Van Oosterhout C, Hutchinson WF, Wills DPM and Shipley P (2004). MICRO-CHECKER: software for identifying and correcting genotyping errors in mirosatellite data. Mol. Ecol. Notes 4: 535-538. 
Walter R and Epperson BK (2001). Geographic pattern of genetic variation in Pinus resinosa: area of greatest diversity is not the origin of postglacial populations. Mol. Ecol. 10: 103-111.

Wu X, Yan MJ and Li ZJ (2010). Genetic structure of mandarin fish Siniperca chuatsi in different geographic populations along the middle and lower reaches of Yangtze River Basin. Acta Hydr. Sinica 34: 843-850.

Xie S, Li Z, Cui Y, Lei W, et al (2003). A New Aquaculture Model in Freshwater Lakes in China Piscivorous Fish Stocking. In: States of Aquaculture in China (Lee C and Andria V, eds.). The Oceanic Institute, Hawaii, 55-67.

Zane L, Bargelloni L and Patarnello T (2002). Strategies for microsatellite isolation: a review. Mol. Ecol. 11: 1-16.

Zhang B, Li ZJ, Tong JG and Liao XL (2006). Isolation and characterization of 18 polymorphic microsatellite markers in Chinese mandarin fish Siniperca chuatsi (Basilewsky). Mol. Ecol. Notes 6: 1216-1218.

Zhuo XL, Liang RS, Chen YF, Huang GJ, et al. (2012). Genetic characterization of northern snakehead (Channa argus) populations in China using microsatellite markers. Bioch. Syst. Ecol. 43: 25-31. 